\title{
Configurações
}

Revista Ciências Sociais

26 | 2020

Economy and Society: politics, practices, agents, and institutions

\section{O financiamento do comércio da Ásia no último quartel de setecentos}

The financing of Asian trade in the last quarter of the eighteenth century

Le financement du commerce de l'Asie au cours des derniers vingt-cinq ans du

XVIIIe siècle

Tomás Pinto de Albuquerque

\section{(2) OpenEdition}

Journals

Edição electrónica

URL: http://journals.openedition.org/configuracoes/9907

DOI: 10.4000/configuracoes.9907

ISSN: 2182-7419

Editora

Centro de Investigação em Ciências Sociais

Edição impressa

Paginação: 19-41

ISSN: 1646-5075

Refêrencia eletrónica

Tomás Pinto de Albuquerque, «O financiamento do comércio da Ásia no último quartel de setecentos », Configurações [Online], 26 | 2020, posto online no dia 15 dezembro 2020, consultado o 18 dezembro 2020. URL : http://journals.openedition.org/configuracoes/9907 ; DOI : https://doi.org/ 10.4000/configuracoes. 9907 
Albuquerque, Tomás Pinto de - 0 financiamento do comércio da Ásia no último quartel de setecentos. Configurações, vol. 26, 2020, pp. 19-41.

\title{
O financiamento do comércio da Ásia no último quartel de setecentos
}

TOMÁS PINTO DE ALBUQUERQUE*

GHES-CSG/ISEG - Lisbon School of Economics \& Management, Universidade de Lisboa

\begin{abstract}
Resumo
O presente artigo procura apresentar uma nova versão sobre a forma de financiamento do comércio asiático português, reanimado a partir da década de 80 do século XVIII. Nesse sentido, com base num conjunto de livros de contas e carregação dos navios "Trovoada Pequeno" e "Trovoada Grande", detidos por Luís Machado Teixeira e Joaquim Pedro Quintela, procuramos compreender como se financiaram essas viagens e qual o motivo desse surto, quase dois séculos depois da descoberta do caminho marítimo para a Índia.
\end{abstract}

Palavras-chave: Portugal, comércio, Oriente, financiamento, chá.

\begin{abstract}
The financing of Asian trade in the last quarter of the eighteenth century The present article aims to present a new version of the financing of the Asian-Portuguese market, revived in the 80 s of the eighteenth century. Considering the accounting and cargo books of the ships "Trovoada Pequena" and "Trovoada Grande", detained by Luís Machado Teixeira and Joaquim Pedro Quintela, we try to understand how these trips were financed, and what was the motive of this outbreak, almost two centuries after the discovery of the sea route to India.
\end{abstract}

Keywords: Portugal, trade, Orient, financing, tea.

*E-mail: tomaspintodealbuquerque@gmail.com 


\begin{abstract}
Résumé
Le financement du commerce de l'Asie au cours des derniers vingt-cinq ans du XVIII siècle

Cet article vise à présenter une nouvelle version sur le mode de financement du marché asiatico-portugais, relancé depuis les années 80 du XVIIle siècle. Dans ce sens, à partir des livres de comptes et du chargement des navires «Trovoada Pequeno» et «Trovoada Grande», détenus par Luís Machado Teixeira et Joaquim Pedro Quintela, nous essayons de comprendre comment ces voyages ont été financés et quel est le motif de cette flambée, près de deux siècles après la découverte de la route maritime vers l'Inde.
\end{abstract}

Mots-clés: Portugal, commerce, Orient, financement, thé.

\title{
Introdução
}

Passados mais de 300 anos daquele que foi o período áureo do comércio português na Ásia os portugueses voltaram a descobrir a Carreira da Índia. Na segunda metade do século XVIII observa-se um renovado interesse pelo mercado asiático. Porém, este deixara de ser um negócio exclusivo da Coroa, havendo um maior interesse dos privados na aquisição de produtos provenientes da China e da Índia.

A oportunidade gerada pela conjuntura internacional bélica, que ocupou as principais potências europeias, diminuindo a sua atenção a Oriente, surge aos portugueses como uma oportunidade. No contexto interno, Borges de Macedo (1951) apresentou os anos 60 do século XVIII como o início de uma crise económica, sendo as reformas pombalinas aí efetuadas uma resposta a esse contexto, tendo como um dos resultados a abertura do comércio da Ásia. No entanto, num estudo recente Leonor Freire Costa, Maria Manuela Rocha e Rita Martins de Sousa (2013), demonstraram que essa visão não corresponderia à realidade. Aquilo que deixaram claro foi que o contexto reformista levado a cabo por Sebastião José de Carvalho e Melo, sobretudo no que ao comércio diz respeito, foi uma forma de criar oportunidades à aplicação dos capitais, que então tinham sobretudo origem nas remessas de ouro do Brasil (Costa, Rocha e Sousa, 2013: 181-187).

O ressurgir do interesse pelo negócio a Oriente não passou despercebido aos historiadores portugueses que alimentaram um debate sobre as causas do redespertar da Carreira da Índia. Não só procuraram compreender as suas causas, como tentaram também explicar a forma como se financiaram essas viagens, embora, em muitos casos, apenas repetindo teorias já defendidas por historiadores como Acúrsio das Neves (1814). Parece-nos que o mais recente e importante aporte reside no trabalho de Jesus Bohorquez (2020a) que, para além de apresentar uma versão alicerçada numa visão global desse negócio, assenta as suas premissas em fontes primárias. No seu trabalho o historiador apresenta um sistema de financiamento assente numa escala planetária, onde os vários continentes se encontram 
conectados. Assim, os comerciantes partiriam de Lisboa, reunindo ali o capital necessário, tendo ele as mais variadas origens. Dali seguiriam para o Brasil, descontando as letras em prata, depois utilizada para o negócio na Ásia. O objetivo nesse continente seria o de comprar panos, depois reencaminhados a Lisboa. Da casa da Índia eram depois embarcados em direção a África para o escambo dos negros, redirecionados às plantações brasileiras, fechando-se assim o ciclo. No entanto, as suas explicações procuram sobretudo justificar o comércio com a Índia, não contemplando todo o negócio português com o Oriente.

Mas, então, como é que se financiou esse negócio? Terá sido com investimento estrangeiro? Como é que se obtinha prata para esse negócio? Estava o modelo próximo daquele que Bohorquez apresentou para o comércio com a Índia?

Compreender o interesse português na Ásia e mais concretamente em Macau, como se financiou esse negócio e quais os produtos que alimentavam essas viagens nos finais do século XVIII é precisamente aquilo a que nos propomos responder neste estudo. Para isso analisaremos em detalhe os livros de contas de duas negociações, ocorridas entre 1782 e 1785, dos navios "Trovoada Grande" e "Trovoada Pequeno", duas viagens organizadas pelos sócios armadores Joaquim Pedro Quintela e Luís Machado Teixeira, homens de negócio da praça de Lisboa e dois dos mais ricos comerciantes da sua época.

\section{Novas oportunidades a Oriente}

A historiografia é unânime quanto ao facto da década de 80 do século XVIII representar um período de aumento do comércio asiático, no que se entendeu chamar de ressurgimento da Carreira da Índia (Pinto, 1994, 1995; Carreira, 1995; Pedreira, 1995; Alves, 1998; Miranda, 2002; Guinote, Frutuoso e Lopes, 2002; Cunha, 2006a, 2006b; Domingues, 2015; Bohorquez, 2020a). Se no século XVI a Carreira da Índia era a viagem anual organizada pela Coroa ao Estado da Índia, na segunda metade do século XVIII estava transformada num movimento de navios que, quase na sua totalidade, eram financiados pelos privados. Assim, a Carreira da Índia passara a ser, tal como lembrou Amaral Lapa (1968), um percurso entre dois pontos, a ligação por via marítima entre Lisboa e a Ásia. Nesta integravam tanto os espaços coloniais atlânticos, como o Brasil, a Madeira ou a África Ocidental, bem como portos no Índico para onde os navios se dirigiam, seja na África Oriental (Moçambique), seja noutros portos mais orientais que não estavam sob administração portuguesa, como Bengala, Madrasta ou Calcutá, estendendo-se até Macau (Cunha, 2006a: 411).

Pelo estudo efetuado por Guinote et al. (2002: 32-38) ficou demonstrado o incremento do número de navios que saíam dos portos da Ásia em direção a Lisboa no período entre 1780 a 1823. 
Não se pense, no entanto, que esse redescobrimento do interesse português pela Ásia é equiparável ao período inicial do funcionamento da Carreira da Índia. Jorge Viana Pedreira (1995: 336), no seu estudo sobre os comerciantes da Praça de Lisboa, lembra que no cômputo do comércio colonial (onde o Brasil tem um peso determinante) a Ásia apenas representou cerca de 12 a $18 \%$.

Embora a sua importância comercial comparativamente a outros espaços do império português não seja determinante, não deixa de ser imperativo procurar uma explicação para esse ressurgimento.

Tabela 1: Conjunto das viagens com destino a Lisboa no período de 1770-1799

\begin{tabular}{|l|r|r|}
\hline \multicolumn{1}{|c|}{ Porto Origem } & N. ${ }^{\text {V Viagens }}$ & \multicolumn{1}{c|}{$\%$} \\
\hline Macau & 64 & 36 \\
\hline Índia & 48 & 27 \\
\hline Bengala & 35 & 20 \\
\hline Goa & 26 & 15 \\
\hline Outros & 6 & 3 \\
\hline Total & 179 & 100 \\
\hline
\end{tabular}

Fonte: (Guinote, Frutuoso e Lopes, 2002: 223-232).

Através da Tabela 1 conseguimos ter uma ideia do número de navios que se dirigiram a Lisboa. Mas, qual a razão para o interesse dos comerciantes portugueses nos portos a Oriente? São diversas as justificações apresentadas para este ressurgimento. A primeira delas, apontada por Acúrcio das Neves, foi a reforma levada a cabo pelo ministro de D. José I. Sebastião José de Carvalho e Melo seria o principal responsável pelo rejuvenescido interesse dos comerciantes portugueses pelo Oriente. Depois de gorada a sua tentativa de implementar uma companhia de comércio para a Ásia, nos primeiros anos do seu ministério, a sua estratégia mudaria (Neves, 1814: 285-292; Carreira, 1995: 83-84; Pinto, 1995: 218; Cunha, 2006b: 334-335). Sobretudo a partir de 1761 começou a ser produzido um conjunto de leis, decretos, alvarás e avisos, que reconfiguravam e abriam o comércio português a Oriente. Ainda em 1755 abriu-se o comércio moçambicano a todos os moradores da Ásia portuguesa, seguindo-se, em 1761, a abertura do comércio entre Angola e Moçambique, bem como, a permissão aos navios que seguiam a Rota do Cabo, de aportarem a Luanda. Em 1765 coloca-se fim à navegação em frotas (Cunha, 2006a: 396-399).

Ernestina Carreira (1995: 83-84) corrobora esta ideia mas, segundo a autora, o principal motivo do redespertar do interesse português pelo Oriente prende-se com o contexto político europeu. Afirma que, na segunda metade do século XVIII, os conflitos bélicos que decorreram entre as potências europeias e a contínua 
neutralidade de Portugal fez com que Lisboa se pudesse transformar numa plataforma de abastecimento, onde os congéneres europeus que tinham deixado de ter acesso direto ao Oriente se podiam abastecer.

De acordo com a historiadora, também o contexto interno do comércio intra-asiático, com a abertura em 1770 pela Companhia das Índias Inglesa (EIC) ao comércio dos privados ingleses nas costas indianas, terá sido um fator de importância. Na sua ótica isto foi uma oportunidade para os comerciantes portugueses de Lisboa e da Índia, "que começaram rapidamente a exportar para Macau, por conta própria ou com capitais britânicos" (Carreira, 1995: 85).

Estas são ideias suportadas tanto por Celsa Pinto como por João Manuel de Almeida Teles da Cunha, que, ao argumento para a justificação do "ressurgimento", acrescentam o interesse tanto de nacionais como de estrangeiros em financiar viagens a partir de Lisboa, sobretudo fintando o monopólio da Companhia das Índias Inglesa (Pinto, 1995: 218; Cunha, 2006b: 333), que depois da batalha do Plassey, em 1757, consolidou a sua posição de potência dominante na Índia (Pinto, 2006: 339).

Esse interesse estaria sobretudo ligado ao comércio dos panos asiáticos, primeiro os de algodão estampados e, depois, os não tingidos ou crus que eram estampados no reino e reexportados para o Atlântico Sul (Pedreira, 1991: 540-544; Cunha, 2006b: 338). Pinto (1995: 219) aponta que 95\% das importações feitas a partir de navios despachados dos portos da Índia para Lisboa correspondiam a isso mesmo. Este argumento historiográfico é sustentado pelos dados apresentados na Tabela 1, onde se observa uma primazia dos vários portos indianos nas saídas para Lisboa. Se somarmos os portos referidos na generalidade como Índia, com $27 \%$, os de Bengala e Goa, com 20 e 15\% respetivamente, vemos que essa região é de facto a responsável pelo maior número de despachos, com $62 \%$.

Compreendendo a importância desse comércio, Jesus Bohorquez (2020a: 19-20) chama a atenção para a sua escala global. O autor demonstra uma relação direta entre o aumento do interesse no comércio de panos da Índia e o negócio do tráfico de escravos para o Brasil, sobretudo na segunda metade do século XVIII. No entanto, estão ainda por aclarar quais os motivos do interesse dos portugueses em Macau, representando 36\% das viagens com direção a Lisboa.

\section{0 financiamento da viagem}

Apresentadas as causas do desencadear do movimento que leva à redescoberta do comércio oriental por parte dos portugueses, falta, então, responder de forma mais concreta à questão de como é que se financiaram essas viagens.

É aceite pela historiografia que para o negócio na Ásia eram precisos elevados capitais e uma rede estruturada. As despesas da armação e o risco impunham a necessidade de cooperação. A rede ajudava a estruturar a organização a Oriente, ao garantir contactos que permitissem o acesso às mercadorias pretendidas, bem 
como à prata, elemento fundamental para os negócios com a Ásia. Acúrcio das Neves (1814: 280), escrevendo sobre esse comércio no século XIX é perentório na sua afirmação: "Armam-se estas negociações em Lisboa com letras de Inglaterra". O papel dos capitais estrangeiros no financiamento do negócio a oriente foi também apontado por outros, como já dissemos (Carreira, 1985: 85; Pinto, 1995: 218; Cunha, 2006b: 333).

Nesse sentido vai o estudo de Ernestina Carreira (1995: 87) sobre as famílias Loureiro e Ribeiro Neves. Neste, a historiadora procura demonstrar a rede de contactos que as duas famílias construíram desde a Europa à Ásia, sem esquecer o Brasil e a África, no sentido de assim conseguirem canalizar capitais e escoar as mercadorias. Entre as principais mercadorias da torna viagem estavam a pimenta e café, embarcadas a partir de Bombaim e os panos provenientes das feitorias portuguesas de Damão e Surrate.

Jorge Pedreira (1995: 336-338) concorda com a complexidade que o negócio impunha, pela logística que requeria, pelo elevado capital que exigia, pelos riscos que acarretava. Estas eram as medidas da sua atração e repulsa. Se, por um lado, os riscos podiam ser dissuasores da participação, por outro, os ganhos podiam ser elevadíssimos. Assim, todos aqueles que podiam participavam, mas aqueles que maior acesso tinham eram precisamente os grandes comerciantes, por reunirem capitais e redes.

Relativamente às formas de financiamento, Pedreira (1995: 352-353) apontou vários mecanismos. $\mathrm{O}$ primeiro eram as letras de risco, uma das formas de crédito onde se financiavam as viagens contra um prémio nunca inferior a $30 \%$, ocorrendo, normalmente, o pagamento trinta dias passados da chegada a bom porto. Os possíveis atrasos nesse pagamento resultariam no acréscimo de um juro de mora de $5 \%$ sobre o capital e prémio. Aqui contemplavam-se alguns riscos como de naufrágio, fogo e aprisionamento por inimigos, que ocorrendo, contemplariam a perda total de capital e prémio, ficando o tomador isento. Contudo, em certos casos, em vez de se avançar com o dinheiro, eram adiantadas as mercadorias, que corriam com um prémio de risco de $35 \%$, a pagar no regresso.

Outra das formas era a concessão de empréstimos, dando-se como garantia o frete do navio. Neste caso, o frete a cobrar funcionava como o colateral que suportava o empréstimo. Pedreira (1995: 354-355) analisou também um outro instrumento, as letras de favor. Estas eram uma espécie de título executório, passado por um comerciante a um outro, que não recebia dinheiro ou mercadorias, mas apenas um título de obrigação. Segundo o autor, este era um mecanismo fácil para obter dinheiro fresco. Essas letras eram rapidamente descontadas e utilizadas para acudir a qualquer necessidade.

Teles da Cunha e Celsa Pinto, como já referido, deixam antever a existência de interesses ingleses a financiar estas viagens, seja para o negócio na Ásia, seja para o negócio na China. No entanto, não deixam claro como é que esse financiamento se processava. 
Jesus Bohorquez (2020a) deu recentemente um importante aporte a esse respeito. Analisando um conjunto de viagens tendo como destino o comércio asiático, concluiu que na sua maioria foram financiadas por contratos marítimos, onde os capitais com diferentes origens europeias e asiáticas, se reuniam em Lisboa. Assim se obtinham os recursos para dar início ao percurso que seguia da metrópole diretamente ao Rio de Janeiro, onde se embarcava a prata, originária das Índias de Castela, que era fundamental no comércio com a Ásia. Ali chegados, proceder-se-ia à compra dos têxteis, que eram depois enviados de volta ao reino, devendo dar entrada na Casa da Índia. De Lisboa seguiam os navios negreiros com a carga de panos em direção a África, onde adquiriam os nativos, que eram posteriormente encaminhados para o Brasil, fechando-se dessa forma o ciclo (Bohorquez, 2020a: 30-37).

Se, por um lado, isto explica os números apresentados para as viagens aos portos do subcontinente indiano, falta, por outro, explicar os números que apresentámos quanto às viagens realizadas a partir de Macau, bem como, o financiamento dessas viagens, uma vez que, os produtos ali adquiridos não eram utilizados no comércio africano, estando pois apartada a solução explicativa apresenta por Bohorquez (2020a).

Com o intuito de oferecer uma solução para ambas as premissas, debruçamo-nos sobre o estudo dos livros das negociações dos navios "Trovoada Grande" e "Trovoada Pequeno", que nos anos 80 do século XVIII empreenderam viagens a Macau. No entanto, a inexistência de séries completas dos livros que compunham o registo de toda a operação obriga-nos a recorrer a uns e outros, sem podermos fazer um estudo de cada viagem de forma independente.

\section{A preparação da viagem}

O primeiro passo a dar na organização da viagem era o pedido de uma licença' à Junta do Comércio, imposição feita pelo Alvará de 24 de novembro de $1770^{2}$. Era uma forma da Coroa e da própria Junta controlarem quem tinha acesso ao comércio. No sentido estrito do termo, a licença era uma autorização, mas no sentido mais lato, a Coroa e os homens de negócio, representados na Junta, influenciavam de forma evidente quem podia ou não ter acesso, garantindo os seus interesses pessoais, bem como os das suas redes e parceiros de negócio. Além disso, esta era ainda uma forma de garantir que quem patrocinava as viagens eram homens de largo capital, delimitando-se que apenas aqueles que tivessem um fundo de maneio superior a 120 contos de réis poderiam patrocinar a armação evitando-se negócios ruinosos. 
Assim, não é de estranhar que a armação destes navios tenha sido feita precisamente por Joaquim Pedro Quintela e Luís Machado Teixeira. As suas posições na praça do comércio lisboeta colocavam-nos entre os mais ricos e influentes homens, o que lhes garantia os requisitos necessários para obter a referida licença: capital e redes.

Os livros do navio "Trovoada Pequeno" permitem-nos perceber como é que se constituía o capital em Lisboa, antes de se iniciar uma viagem. Era, pois, da responsabilidade dos armadores a organização da empresa. O navio era pertença de Luís Machado Teixeira, um dos sócios principais. No caso português esta era uma prática normal (Pedreira, 1995: 341). Mas a necessidade de cooperação impunha-se, decorrente da exigência dos capitais e o elevado risco, o que levava a que a negociação fosse aberta a outros. O seu parceiro principal foi Joaquim Pedro Quintela. A eles correspondia grande parte do capital reunido em Lisboa, logo na primeira viagem feita, em 1782, pelo navio "Trovoada Pequeno", como evidenciado pela Tabela 2.

Tabela 2: Investimentos feitos no navio "Trovoada Pequeno"

\begin{tabular}{|l|r|r|}
\hline \multicolumn{1}{|c|}{ Investidores } & Valor (réis) & $\%$ \\
\hline Luís Machado Teixeira & 56802,28 & 18 \\
\hline Joaquim Pedro Quintela & 89969,98 & 29 \\
\hline Demais sócios & 162389,47 & 53 \\
\hline Total & 309161,73 & 100 \\
\hline
\end{tabular}

Fonte: ANTT, Feitos Findos, Livros dos Feitos Findos, Livro 35.

A viagem do "Trovoada Pequeno" (1782-1784) acabou por ser alargada a 35 pessoas. O valor total reunido em Lisboa foi de 309.161,73 réis. Desse valor, 56.802,28 réis pertenciam a Machado Teixeira e 89.969,98 réis a Quintela, compreendendo $47 \%$ do capital. O restante investimento foi reunido pelos demais 35 sócios desta viagem, respeitando $53 \%$ do investimento $\left(162.389,47\right.$ réis) ${ }^{3}$.

Relativamente à composição do grupo de sócios, temos aqueles que investiram individualmente, a quase totalidade dos ativos, mas também aqueles que investiram em parceria com outros, havendo cerca de 6 sociedades representadas. Todos os investidores eram homens. Embora fossem maioritariamente comerciantes, também vemos funcionários da coroa, militares e desembargadores a investir. Eram, quase na sua totalidade, de origem portuguesa, estando apenas presentes três estrangeiros (dois alemães e um italiano) que não representavam mais de $1 \%$ do capital investido. Ainda a propósito da composição acionista, parece-nos relevante dar conta que tanto o capitão do navio, como os sobrecargas tinham a sua 
quota de investimento. Esta era uma forma de garantir que também eles pudessem beneficiar do empreendimento, ao mesmo tempo que se minimizava o risco de uma conduta desviante ou de deslealdade, incrementando a possibilidade de sucesso da negociação. Evitavam-se, também, eventuais problemas de agência.

Pelo que depreendemos da análise dos livros, o capital era entregue aos armadores que compravam os bens na China, remetendo-os depois a Lisboa. Isto fica claro sobretudo pelos recibos dos navios e respetivas contas. Esta ideia é reforçada pelos recibos das contas finais da navegação onde, depois de feitas as vendas na Casa da Índia, se fazia um balanço das dívidas e a quem deviam ser pagas, correspondendo os valores em falta aos aportes feitos por cada investidor.

Esta ideia é reforçada pelo modelo societário que supomos estar na base desta negociação. No nosso entender, o mais provável é que essa fórmula correspondesse às práticas da Praça de Lisboa. Falamos, pois, da sociedade em comandita. Não tendo sido encontradas referências à celebração de escrituras destas sociedades entre os registos notariais de Lisboa, podemos propor que estas tenham sido criadas a título particular. Atente-se que, à data, não era ainda (tal como é hoje) exigida a forma escrita e registada, para formalizar a constituição de uma sociedade comercial.

Como dissemos, Bohorquez apresentou o contrato marítimo ${ }^{4}$ como o modelo que subjaz às sociedades que analisou para o comércio asiático. No entanto, isso está em contra corrente com o que sabemos sobre as práticas societárias portuguesas, mas também com o levantamento que fizemos nos documentos encontrados.

Na essência, a sociedade em comandita traduz-se num contrato onde uma parte, o sócio comanditado, recebe dos demais o capital, obrigando-se a gerir a empresa e a partilhar com o(s) sócio(s) comanditário(s) os lucros. Este(s) tinha(m) uma responsabilidade limitada ao aporte feito por cada um (Gonzáles de Lara, 2018: 71-72). Começou por ser entendido como um contrato de serviços, mas evoluiu ao longo do tempo para um investimento por ações. O resultado era uma sociedade em comandita que juntava vantagens do contrato marítimo, mas também da companhia. Compreendia uma responsabilidade limitada para o investidor; permitia algum grau de liquidez a partir da transmissão da quota detida; esboçava um princípio de responsabilidade da empresa perante terceiros, compreendendo já a sociedade enquanto ente e, portanto, separando entre o que

\footnotetext{
4 Este modelo de contrato remonta as suas origens até à Antiguidade. Era utilizado sobretudo para financiar viagens marítimas com elevado risco. Estava próximo do contrato de mútuo, onde mediante o empréstimo de dinheiro se vencia um juro. No caso do contrato marítimo, existiam pelo menos duas modalidades, uma que era o empréstimo de dinheiro, sob o pagamento de um prémio, outra era aquela onde se adiantavam as mercadorias, mediante o pagamento de um prémio de risco, um modelo desenvolvido pelos portugueses e chamado de respondência. No entanto, o pagamento do capital e prémio, estavam dependentes da chegada a bom porto da negociação em causa, apenas havendo suspensão do mesmo em caso de naufrágio, incêndio ou pirataria, correndo esse risco pelo investidor (Gonzáles de Lara, 2018: 67-69; Harris, 2020: 112-118).
} 
eram os acionistas e o que era o capital; e permitia já uma imobilidade do capital, seja pela duração de um ano ou vários. No entanto, pressupunha ainda uma partilha de responsabilidades entre o sócio comanditário/administrador e a empresa, sendo o primeiro responsabilizável pela segunda. Impunha-se também, quanto à transmissibilidade, que tivesse autorização dos demais parceiros para que ela se efetivasse (Roover, 1963: 50-53, 70-74; Costa, 2002: 399-401; Gonzáles de Lara, 2018: 74-75; Harris, 2020: 130-136).

No caso português este modelo foi aplicado tanto nas rotas atlânticas como nas asiáticas (Costa, 1997: 201, 2002: 391-413, 2013: 38-61). Leonor Freire Costa (2002: 395-396) dedicou algum do seu trabalho a estudar as questões ligadas ao transporte e chamou a atenção para a utilização desse tipo de sociedades, tanto para ajustar as partes sobre a construção dos navios, como para o comércio atlântico ou asiático. Neste caso esse modelo foi utilizado no comércio da Carreira da Índia, onde o Rei participava na empresa como se de um sócio comanditário se tratasse, partilhando investimento e risco com os privados (Costa, 1997: 201, 2013).

No caso específico das viagens dos "Trovoada", pela informação dos livros de contas podemos depreender que os sócios comanditados da empresa eram os seus principais investidores, Joaquim Pedro Quintela ${ }^{5}$ e Luís Machado Teixeira ${ }^{6}$. Esta ideia parece ser claramente justificada dado que, além de terem investido a maior fatia do capital, a licença emitida pela Junta do Comércio conferia-Ihes a responsabilidade da organização da viagem. Além disso, segundo os livros de contas era sobre Quintela e Teixeira - nunca sobre os demais sócios - que recaía o risco7; e era a estes que cabia a função de liquidação das respetivas viagens.

Reunido o capital era preciso dar seguimento à viagem. Mas, como é que tal se processava? Esse capital ia sob a forma de letras a descontar num qualquer porto asiático? E se sim, como eram descontadas em locais longínquos? Ou era convertido em prata para depois adquirir os produtos na China? Qual o papel das redes neste processo? Como é que os portugueses solucionaram estes problemas?

\footnotetext{
5 Era neto de comerciante, filho de funcionário da coroa e sobrinho e herdeiro de um dos maiores capitalistas de Lisboa no tempo de Pombal, Inácio Pedro Quintela. Dele recebe os bens e a posição social que o vão colocar entre os mais proeminentes homens de negócio da praça de Lisboa e detentor de uma das maiores fortunas do país, onde cabem as sociedades da Pesca das Baleias, do Estanco do Sal, do Tabaco, dos Dízimos do Brasil ou dos Diamantes (Costa, 1992; Pedreira, 1995; Madureira, 1997; Albuquerque, 2019).

6 Filho de um comerciante da Baía, João Machado Miranda, que envia o seu filho a Coimbra, onde se torna doutor de capelo vindo a ser leitor no Desembargo do Paço. Quando o seu pai morre regressa à Baía assumindo os negócios, na sua maioria ligados ao comércio de escravos. No período que estudamos está já entre os principais negociantes da praça de Lisboa, dedicando-se também ao investimento em manufaturas. Foi proprietário de vários navios para além do "Trovoada Grande" e "Trovoada Pequeno", como o navio "São Luís" e "Santa Maria Madalena", o navio "Vigilante" (em sociedade com Joaquim Manuel dos Santos e Diogo Francisco dos Santos), a galera "Carolina", entre outros. Ocupava-se, então, não só do comércio com a Ásia, mas também com o Brasil. ANTT, HOC, Letra L, mç.10, n. 12 (1775); ANTT, Junta do Comércio, Livro 123, fl. $112 \mathrm{v}$.

7 ANTT, Feitos Findos, Livros dos Feitos Findos, Livros 23, 24, 26, 39, 40, 41.
} 


\section{0 negócio na Ásia}

Embora, como vimos, diversos historiadores tenham tentado chegar a uma solução para estas questões, a análise crítica do registo do navio "Trovoada Pequeno" oferece-nos uma nova perspetiva.

Bohorquez (2020a) deu-nos conta de que as letras reunidas em Lisboa serviam ou para ser descontadas no Rio de Janeiro, garantindo a obtenção de prata, ou eram deduzidas nos portos da Ásia, para esse mesmo efeito. Era por isso fundamental a existência de uma estrutura assente num grande número de correspondentes (Bohorquez, 2020a).

No entanto, não é isso que os livros de contas da negociação do "Trovoada Pequeno" nos dizem. Pelo que depreendemos da nossa análise, esse capital inicial era maioritariamente convertido num conjunto de mercadorias europeias ${ }^{8}$ como cobre, ferro, peças de lonas, âncoras, pregos, alcatrão, peixe, fio de vela, barris de alvaiade (chumbo), barris de azarcão ${ }^{9}$, cabos, peças de caxemira e barris de cochinilha ${ }^{10}$.

Tabela 3: Cargas e valores a bordo do navio "Trovoada Pequeno" (1782-1784)

\begin{tabular}{|l|l|r|}
\hline \multicolumn{1}{|c|}{ Local } & \multicolumn{1}{c|}{ Tipo carga } & Valor (réis) \\
\hline Lisboa & Géneros & 51059,892 \\
\hline Madeira & Vinho & 19740 \\
\hline Rio de Janeiro & Água Ardente & 296,912 \\
\hline Madrasta & Alvaiada & 633,055 \\
\hline Madrasta & Azarcão & 1324,298 \\
\hline Madrasta & Lacredas & 36786,4 \\
\hline Madrasta & Algodão & 6225,5 \\
\hline & Total & 116066,057 \\
\hline
\end{tabular}

Fonte: ANTT, Feitos Findos, Livros dos Feitos Findos, Livro 37.

Tabela 4: Dinheiro a bordo do navio "Trovoada Pequeno" (1782-1784)

\begin{tabular}{|l|r|}
\hline \multicolumn{1}{|c|}{ Local } & Réis \\
\hline Lisboa & 4000 \\
\hline Rio de Janeiro & 12000 \\
\hline Total & 16000 \\
\hline
\end{tabular}

Fonte: ANTT, Feitos Findos, Livros dos Feitos Findos, Livro 37.

8 ANTT, Feitos Findos, Livros dos Feitos Findos, Livros 36, 42.

9 Zarcão, derivado de chumbo.

10 Pigmento que de cor azul. 
Como podemos ver pelas tabelas 3 e 4, a maioria da carga embarcada em Lisboa era composta de géneros europeus e apenas uma pequena quantidade de dinheiro. Tal não é uma novidade, pois, como defendeu Ernestina Carreira (1995: 87), esses produtos serviam para o comércio indiano.

Depois de sair da capital do império, a primeira paragem era a llha da Madeira, onde se complementou a carga com vinho madeira. O destino dessa mercadoria foi precisamente o primeiro porto de paragem na Ásia, Madrasta. Essa cidade, sob domínio inglês, recebia o vinho para acudir à demanda criada pelos ingleses que aí se tinham fixado (Carreira, 1995: 87; Cunha, 2006a: 400).

Ainda antes de seguir viagem para a Ásia o navio aportou no Rio de Janeiro, onde carregou cachaça, mas também uma pequena quantia em dinheiro, por conta de Joaquim Pedro Quintela. Só depois de cumpridas estas etapas o navio seguiu em direção ao Cabo da Boa Esperança.

A partir da leitura destes livros observamos que não há qualquer registo da entrada de prata, fundamental para o negócio no oriente. Vitorino Magalhães Godinho (1968) foi o primeiro a dar conta da diminuição dos afluxos de prata espanhola à Europa a partir da segunda metade do XVII e princípio do XVIII. Pegando nessa questão, mais recentemente, Rita Martins de Sousa (2011) analisou os registos da Casa da Moeda onde se assentam as entradas da prata em Lisboa. A historiadora afirma que, de facto, se verifica uma escassez no período identificado por Godinho, mas que a partir de 1713, com a assinatura do Tratado de Utrecht e a passagem da Colónia do Sacramento para administração portuguesa, a prata espanhola passa a ser enviada a Lisboa a partir do Rio de Janeiro (Sousa, 2011: 393). Esta ideia é reforçada pelos trabalhos de Bohorquez (2020a, 2020b), o que por um lado estabelece o Rio de Janeiro como a principal fonte de acesso à prata pelos navios que saiam de Lisboa, e por outro tornam-no o principal centro de fornecimento de prata à metrópole.

Contudo, como vimos, no momento da travessia do oceano Atlântico o navio "Trovoada Pequeno" não transportava prata. Assim, atendendo às mercadorias embarcadas, nomeadamente as de origem europeia, sugerem-nos uma outra hipótese. Sabemos que esses produtos eram enviados para serem vendidos na Ásia, porém não tinham como destino os portos do Estado da Índia, mas antes a cidade portuária de Madrasta (atual Chennai). Os artigos aí vendidos eram a garantia da obtenção do capital necessário para depois comprar outras mercadorias mais a Oriente, na China.

Esta nossa teoria é reforçada pela historiografia. A prata era conseguida nos portos indianos sob domínio inglês. As cidades do Golfo de Bengala eram os principais pontos de concentração da prata, a qual era trazida pelos europeus, sobretudo pelas Companhias Inglesa e Holandesa. No caso da VOC correspondia a mais de 50\% dos produtos por ela introduzidos na Ásia (Chaudhuri, 1998: 86). Já no caso inglês, a prata era trazida pela companhia, embarcada a partir de Londres, 
que funcionava como um importante centro de distribuição desse metal precioso (Sousa, 2011: 392).

Mas a estes portos chegava também o metal branco resultante do comércio intra-asiático, com as mais variadas origens, uma realidade que não começa apenas com a presença europeia, tendo já tradições anteriores (Chaudhuri, 1998: 92-93).

Pelos livros de contas e carregação dos navios "Trovoada" sabemos que estes artigos tinham já um destino e que era responsabilidade dos sobrecargas contactar os destinatários e vender-lhes os respetivos bens. Em Madrasta tinham como correspondentes António de Sousa (português), Chocapá Chety (indiano), Smith Naval (inglês), Robert Barclay (inglês) e John Thompson (inglês) ${ }^{11}$. Todos eram comerciantes e desenvolviam as suas atividades no Oriente. Embora não tenhamos conseguido obter informações sobre todos estes indivíduos, sabemos que tanto Robert Barclay, como John Thompson estavam ligados à administração da Companhia das Índias Inglesa' ${ }^{12}$. Neste mesmo porto eram ainda deixadas mercadorias a entregar a José Barreto, provavelmente um português que, sediado em Calcutá, mantinha negócios na Ásia'³.

Foi desta forma que Quintela e Teixeira contornaram as dificuldades de acesso à prata ou a necessidade de terem que enviar dinheiro sob a forma de letras. $\mathrm{O}$ dinheiro reunido em Lisboa era convertido em mercadorias a serem vendidas na Índia. Mediante a venda desses itens a destinatários específicos no porto de Madrasta obtinha-se, então, a prata e as letras necessárias para as trocas a Oriente. As letras endossadas sobre comerciantes reconhecidos no Oriente, ou então sobre Quintela e Teixeira, eram depois descontadas em Macau, junto dos seus correspondentes ${ }^{14}$.

Mas, será que esta foi uma prática apenas seguia por estes dois comerciantes? Claramente que a resposta é negativa. Por um lado, certamente que as viagens empreendidas pela mesma parceria Quintela e Teixeira utilizaram os mesmos moldes, premissa que se nos torna impossível confirmar uma vez que não tivemos acesso ao mesmo tipo de livros do "Trovoada Pequeno", que nos permitisse chegar a essa conclusão.

Podemos, no entanto, olhar para outras viagens, como aquelas desenvolvidas pela Companhia Geral do Grão-Pará e Maranhão (CGPM) e pela Companhia Geral do Pernambuco e Paraíba (CPP).

11 ANTT, Feitos Findos, Livros dos Feitos Findos, Livros 37, 40.

12 É apontado para um cargo da mesma companhia em 1790, tendo já ligação à mesma. Vide, East India Company, Commission Appointing Robert Barclay Lieutenant of Infantry, James Marshall and MarieLouise Osborn Collection, Beinecke Rare Book and Manuscript Library, Yale University.

13 ANTT, Feitos Findos, Livros dos Feitos Findos, Livro 40.

14 Foi precisamente esse o caso de Francis de Labour, comerciante de origem francesa sediado em Madrasta com uma importante casa de comércio. Quando chega o navio, adquire 75 barris de vinho Madeira, que paga precisamente em dinheiro e letras sobre Bangala e Calcutá, ou seja, sobre comerciantes ingleses. Esses títulos eram facilmente descontados, em qualquer praça com presença de comerciantes europeus com casa no Oriente. ANTT, Feitos Findos, Livros dos Feitos Findos, Livro 42, fls.8-9; Madras Tercentenary Celebration Committee. The Madras Tercentenary Commemoration Volume, Asian Educational Services, 1994. 
Pouco sabemos sobre essas primeiras viagens levadas a cabo pela CGPM, tendo a primeira tido lugar em de $1759^{15}$. António Carreira (1988: 315) dá-nos conta que depois dela ocorreram mais duas, ainda durante a vigência do monopólio, findado em 1777. Uma delas foi a de 1761, com um rendimento de aproximadamente 130 contos de réis (Carreira, 1988: 315). Mas a que melhor analisou foi a realizada em 1781. Segundo o historiador, foi pedida autorização pelos administradores da liquidação das sociedades para que se empreendesse a viagem. Tal foi autorizado pela rainha nos decretos de 22 de fevereiro e 11 de março desse mesmo ano. 0 financiamento fez-se com a emissão de 730 ações, das quais 569 tinham o valor nominal de 200 mil réis e as restantes 161 o valor nominal de 400 mil réis, pelo que foi reunido um capital de 178.200 .000 réis, com um total de 73 acionistas (Carreira, 1988: 316). Relativamente à composição da carga, dá conta que saíram de Lisboa 28.454.051 réis em fazendas, além de 96.000 .000 réis de ouro e prata de (Carreira, 1988: 317).

Ao dar conta da rentabilidade da negociação diz-nos que tiveram um lucro bruto de 267.366 .034 réis aos quais, abatendo os 178.200 .000 réis de capital investido, dá o valor de 89.166 .034 réis o que corresponde ao capital distribuído pelas ações, ou seja, cerca de $50 \%$ do investimento.

Essas viagens foram também postas em prática pela Companhia Geral do Pernambuco e Paraíba. Thiago Alves Dias (2019) aborda precisamente o tema da organização e financiamento de viagens que a companhia realizou à Ásia, através da análise dos livros da negociação das naus "Neptuno" e "Polifemo", datados de 1777. Depois da autorização concedida em 1775, pela qual se previa que apenas uma nau fosse aos portos da Ásia, os planos sofreram algumas alterações, por conveniência da Junta Liquidatária, mas também da Coroa, que participava na empreitada. Assim, as naus apenas partiram de Lisboa em 1777. A nau "Neptuno" saiu da metrópole em direção ao Rio de Janeiro, aportou a Moçambique, de onde seguiu para o Estado da Índia, efetuando paragens em Diu, Damão, Surrate e Goa. Daí partiu para Madrasta, de onde tomou rumo a Macau. Já a sua irmã "Polifemo", depois de abandonar a capital do reino, dirigiu-se à Baía. Daí seguiu em direção ao Cabo da Boa Esperança e aportou em Moçambique, de onde se dirigiu depois a Goa (Dias, 2019: 160-161).

Quando partiram da Europa as suas cargas eram constituídas na totalidade por produtos europeus como: missangas, avelórios, vidros da Boémia, açafrão, água de cheiro, vinho, azeite, pólvora, espingardas, ferro, chumbo, cobre, pregos, chapéus, barras, chapas, papel e corais. Completam as duas cargas o valor de 191.680.958 réis a que se somam 1.016 patacas de prata castelhana. A "Neptuno" completou a sua carga no Rio de Janeiro com açúcar e água ardente, além de mais 20 mil réis de prata castelhana (7.422 pesos). Já a "Polifemo" adquiriu tabaco por conta da Fazenda Real na Baía (Dias, 2019: 161). Como podemos, então, concluir a 
quantidade de prata reunida no Rio de Janeiro não era suficiente para a aquisição dos efeitos chineses. Ora, também aqui nota Alves Dias (2019) que os produtos europeus, bem como os brasileiros, eram vendidos ao longo do percurso, primeiro em Moçambique, embora com maior dificuldade e depois na Índia, com especial destaque para Madrasta, com o intuito de recolher prata. Coincidência ou não, os sobrecargas da nau "Neptuno" foram recomendados a António de Sousa, precisamente o mesmo homem que identificamos no caso da viagem do navio "Trovoada Pequeno" (Dias, 2019: 163).

Dias (2019: 164) termina a sua análise dando conta que no final da negociação, ela teve um lucro líquido de 122.923.125 réis, decorrentes da venda dos produtos chineses em Lisboa, na sua maioria loiças, porcelanas e chá.

Esta não era uma estratégia exclusiva dos portugueses, tendo também outras potências europeias aproveitado a oportunidade e participado no comércio oriental. Disso mesmo nos dá conta Teles da Cunha (2006a: 383), relativamente à Dinamarca que, entre o final do século XVIII e princípio do século XIX, terá tido cargas no valor de 2 milhões de florins. Essa foi também a prática recorrente nas viagens da Companhia Sueca das Índias Orientais. Fundada em 1732, com uma licença de 15 anos de monopólio, a empresa era uma sociedade em tudo semelhante aos modelos inglês e holandês. O trabalho de Koninckx (2007) sobre a empresa sueca é claro. Os produtos que ela transportava nas viagens entre a Europa e a Ásia eram todos de origem europeia. Tinham como fim a Índia, de modo a obter a prata necessária para comprar produtos na China, mais concretamente o chá. Deste modo resolviam a falta de acesso à prata espanhola, que, como temos vindo a observar, era um elemento fundamental para comerciar a Oriente (Koninckx, 2007: 223-ss).

\section{Macau, às portas da China}

Explicadas as conjunturas que permitiram aos portugueses o retomar do interesse na Rota do Cabo e demonstrada uma outra forma de financiar o comércio com o Oriente, parece-nos ainda faltar um esclarecimento quanto ao interesse em Macau. Para isso é determinante perceber o papel que essa cidade e os seus homens de negócio tinham para ultrapassar a barreira do Sistema de Cantão ${ }^{16}$.

16 Macau esteve durante quase 500 anos na dependência dos portugueses, mas a sua localização geográfica manteve-a numa enorme dependência face à China. A partir de 1757 viu um incremento da sua importância sobretudo depois da implementação do Sistema de Cantão. Esta é a expressão da política levada a cabo pela dinastia Quing que abria o porto ao comércio estrangeiro, mas ao mesmo tempo proibia a sua presença em território chinês. Assim, Macau tornara-se um espaço estratégico determinante no comércio com a China, para todos os europeus que ali tentavam fazer negócio. Grande parte desse sucesso coube aos comerciantes da cidade, pois a sua capacidade de adaptação aos contextos ao longo do tempo, colocou a Macau com um interposto entre a China e a Europa, além das suas relações comerciais se estenderem a grande parte da Ásia. No que toca ao comércio de Macau, este estendia-se desde as Ilhas Maurícias até Manila. Destaca-se a Cochinchina, a Índia, a Malásia e Manila. No que toca á Índia há uma perda de importância em favor dos 
Por um lado, a Cidade do Nome de Deus tinha uma posição privilegiada com a China, pois agia como interlocutora entre o Império do Meio e os Europeus. Por outro, os seus comerciantes detinham capital que lhes permitia fazer comércio com toda a Ásia. No século XVIII estabeleceram negócios com a Costa de Bengala, com as famílias indo-portuguesas estabelecidas na Costa do Coromandel, como foi o caso de Calcutá, mas também com a própria companhia inglesa, sem esquecer os comerciantes britânicos que, depois de 1770, faziam o seu negócio privado (Cunha, 2006a: 390-391).

Mas só isso não é suficiente para compreendermos o porquê de Macau ser um dos portos de interesse. Mais uma vez recorremos a Teles da Cunha. Segundo o autor, seriam os comerciantes ingleses que procuravam, a partir de Lisboa, introduzir produtos chineses no velho continente, "contornando [assim] o monopólio da EIC para abastecer a Europa, com destaque para o chá" (Cunha, 2006b: 333).. Segundo o mesmo autor, parte dos navios enviados para Macau tinham capital português, nomeadamente com origem no Brasil, mas também investimento estrangeiro, tanto inglês como francês, havendo ainda capitais espanhóis, gaditanos e italianos, neste último caso com especial destaque para os genoveses (Cunha, 2006b: 334).

Como pudemos verificar, no caso do "Trovoada Pequeno", a maioria dos capitais era português, apesar de haver a presença de outros estrangeiros. Esse foi também o caso das viagens feitas pelas companhias portuguesas. Não negamos que num estudo que abarque uma maior quantidade de viagens se possa detetar a presença de capital estrangeiro com mais expressão, tal como Bohorquez verificou para o negócio dos panos. No caso do negócio do chá e demais produtos chineses, os portugueses investiam nestas viagens, sendo depois a partir de Lisboa que distribuíam os produtos obtidos. O chá surge como uma enorme oportunidade, sobretudo porque, a partir de Lisboa, os europeus o podiam introduzir nos mercados inglês e americano, por via legal ou ilegal, as mercadorias que conseguiam em Lisboa a um menor preço do que os obtidos através da EIC.

Até à data, o principal produtor e fornecedor europeu eram as colónias inglesas da América do Norte, que, em 1776, se revoltaram contra a metrópole, dando-se início à Guerra da Independência, que resultara na criação dos Estados Unidos da América.

Foi, então, preciso encontrar uma alternativa para alimentar a constante procura. É assim que os países europeus se viraram para a China. Entendendo os portugueses que aquela poderia ser uma oportunidade de negócio, ressurgem

tratos com a Cochinchina e a Malásia. Vide (Pires, 1993; Vale, 1997; Alves, 1998; Figueiredo, 2000; Guimarães, 2000; Miranda, 2002; Souza, 2010; Cranmer-Byang e Wills, 2011).

17 Esta não é uma ideia nova, pois a propósito da criação da Companhia de Ostende em 1722, alguma da historiografia apresenta como causa, precisamente a intenção de um grupo de comerciantes se furtar ao monopólio da companhia inglesa (Dreijer, 2017). 
os investimentos nas viagens privadas para o Oriente (Figueiredo, 2000; Hodacs, 2016).

Esta necessidade de contornar esse monopólio surgia sobretudo associada aos impostos cobrados em Inglaterra sobre esse produto (Pritchard, 1934: 285). Tal gerou uma larga competição entre a EIC que, como já dissemos consolidou a sua posição na Ásia em 1757, e todos os demais europeus. Esta "luta" deu-se por um período de cerca de 30 anos, entre 1762 a 1784, onde nomeadamente a França e a Holanda, mas também o Império Austro-húngaro, a Prússia, a Itália e os Estados Unidos da América, estes últimos sobretudo por via do contrabando, procuraram competir com a companhia introduzindo chá na Europa, mas também na América (Pritchard, 1934: 289-290). A situação só começou a inverter-se com a chegada ao governo inglês de William Pitt, que tomou um conjunto de medidas, nomeadamente a descida de impostos, tentativa de controlar os contratos do chá na China e a abertura dos seus portos apenas aos ingleses. Como consequência direta houve uma descida do contrabando e, assim, um impacto nos negócios dos demais europeus.

Os livros de registos dos navios que temos vindo a tomar como base da nossa análise dão-nos conta da importância de um conjunto de comerciantes portugueses sediados em Macau, na concretização do negócio com os chineses. Eram eles os interlocutores com Cantão.

Era o caso de António José Gamboa e de Manuel Homem de Carvalho, dois homens pertencentes ao grupo dos comerciantes portugueses da cidade de Macau e que eram correspondentes de Quintela. António José Gamboa é apontado como um rico comerciante de ópio e algodão, proprietário de diversos navios. Conseguimos datar a sua atividade em Macau desde 1780. Por via do matrimónio conseguiu ligar-se às famílias de comerciantes reinóis locais, sendo dessa forma que entra no grupo, tal como a maioria dos comerciantes daquela cidade, chegando a ser vereador do Senado de Macau várias vezes (Teixeira, 1969: 52, 278). À semelhança de Gamboa, Manuel Homem de Carvalho não era natural de Macau, mas aí se tinha fixado pelo menos desde 1780, tendo também ele integrado a oligarquia local por via do matrimónio. Estava ligado à família Vicente Rosa, uma das mais importantes da cidade, com bastante peso na administração e relevância nos negócios, sendo genro de Simão Vicente Rosa. Fruto da sua proeminência foi também membro das vereações do Senado (Vale, 1997).

Como podemos perceber, estes eram homens que pertenciam à elite comercial de Macau, a quem estavam ligados por laços familiares, o que lhes permitia ocupar lugares de relevo na governança da Câmara e da Santa Casa da Misericórdia. Este seu estatuto conferia-Ihes acesso às instituições de crédito e por sua vez ao capital (Vale, 1997). Isto mesmo era possível porque, a partir de 1761, a Coroa permitira que a Câmara pudesse fazer empréstimos, prerrogativa que depois se estendeu à Santa Casa da Misericórdia, os chamados ganhos de mar e ganhos de terra. Os primeiros eram assim chamados porque diziam respeitos aos empréstimos feitos 
para a realização de viagens marítimas, os segundos eram para financiamento de outros tipo de atividades (Vale, 2006: 378). Essa posição poderia ser uma das formas encontradas para ter acesso à prata. Os negócios da venda dos produtos europeus na Índia tanto podiam ser feitos de forma a se arrecadar esse metal precioso, como por letras sacadas sobre os armadores, Quintela \& Machado, que depois eram descontadas em Macau, junto dos seus correspondentes. Facilitava-se, assim, o desconto das letras pela prata que posteriormente era empregue no comércio com os chineses.

Esta nossa hipótese é reforçada pelo estudo de António Martins Vale (1997) que aponta os comerciantes de Macau como sendo testas de ferro de vários comerciantes estrangeiros, contraindo empréstimos em seu nome, que depois eram utilizados para financiar negócios com os chineses. Jorge dos Santos Alves (1998) chama também a atenção para a necessidade de rever as posições historiográficas sobre as redes de negócios luso-asiáticas, destacando também ele o papel dos comerciantes portugueses de Macau. A verificação desta hipótese obrigará a uma análise mais cuidada, não só a partir de correspondência à qual, até à data, não tivemos acesso, mas dos registos da própria Misericórdia de Macau. Contudo, parece-nos lícito propor que se esses homens operavam a função de intermediários para os estrangeiros ${ }^{18}$, também o fariam certamente para os portugueses.

Era, deste modo, que se obtinha a prata para comprar aos chineses o chá que depois era vendido à Europa, onde, desde a segunda metade de setecentos, se vinha a observar um incremento da procura por esta mercadoria. Era uma resposta às necessidades do mercado que se virava para o Oriente de modo a colmatar as falhas decorrentes das Guerra de Independência dos EUA, principal produtor e fornecedor deste produto (Figueiredo, 2000; Cranmer-Byang e Wills, 2011). Disso mesmo nos dão conta os registos dos despachos de mercadorias dos navios "Trovoada Pequeno" e "Grande" nas viagens de regresso a Lisboa em 1784, 1785 e 1787. Se parte da carga ficava em terra, não especificando os seus destinatários, outra era diretamente baldeada para navios estrangeiros. Embora na viagem de 1785 a totalidade dos destinos tenham sido portos europeus, ao contrário do que aconteceu na de 1784, já na de 1787 houve um peso significativo dos portos americanos nomeadamente Baltimore, Boston, Filadélfia e Nova lorque.

18 Era o caso de ingleses, arménios, franceses, dinamarqueses, holandeses, suecos, americanos, alemães e os espanhóis de Manila. 
Figura 1: Baldeações em Lisboa em 1784, 1785 e 1787

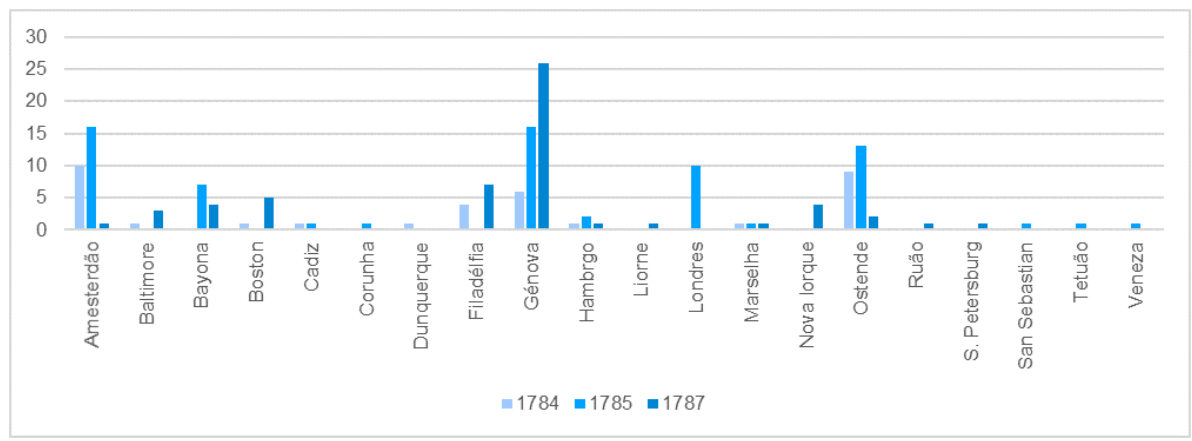

Fonte: ANTT, Feitos Findos, Livros dos Feitos Findos, Livros 43, 23, 49.

Quanto aos produtos, observa-se que o chá é preponderante, como podemos ver pelas Tabelas 5, 6 e 7, embora a carga fosse também composta por outros produtos como panos, sedas, canela, etc.

Tabela 5: Produtos e quantidades baldeadas (1784)

\begin{tabular}{|l|r|c|}
\hline \multicolumn{1}{|c|}{ Produtos } & Quantidade & Unid. Medida \\
\hline Cangas & 9664 & peças \\
\hline Chá & 80460 & $\mathrm{Kg}$ \\
\hline Cetins & 6 & peças \\
\hline
\end{tabular}

Fonte: ANTT, Feitos Findos, Livros dos Feitos Findos, Livro 43.

Tabela 6: Produtos e quantidades baldeadas (1785)

\begin{tabular}{|l|r|c|}
\hline \multicolumn{1}{|c|}{ Produtos } & Quantidade & Unid. Medida \\
\hline Atados & 225 & $\mathrm{Kg}$ \\
\hline Canela & 6000 & $\mathrm{Kg}$ \\
\hline Cangas & 31270 & unidade \\
\hline Chá & 175860 & $\mathrm{Kg}$ \\
\hline Seda & 60 & $\mathrm{Kg}$ \\
\hline
\end{tabular}

Fonte: ANTT, Feitos Findos, Livros dos Feitos Findos, Livro 23. 
Tabela 7: Produtos e quantidades baldeadas (1787)

\begin{tabular}{|l|r|c|}
\hline \multicolumn{1}{|c|}{ Produtos } & Quantidade & Unid. Medida \\
\hline Bengalas & 2701 & unidade \\
\hline Canela & 18180 & $\mathrm{Kg}$ \\
\hline Cangas & 43005 & unidade \\
\hline Chá & 19020 & $\mathrm{Kg}$ \\
\hline Flor de Anis & 120 & $\mathrm{Kg}$ \\
\hline Pimenta & 17460 & $\mathrm{Kg}$ \\
\hline
\end{tabular}

Fonte: ANTT, Feitos Findos, Livros dos Feitos Findos, Livro 29.

\section{Conclusão}

Através deste estudo procurámos dar um contributo para o debate em torno do ressurgimento da Carreira da Índia, que desde o século XIX tem estado nas preocupações dos historiadores portugueses.

O primeiro ponto que nos pareceu importante deixar claro é que não estamos perante um reflorescimento da Carreira nos moldes do século XVI. No século XVIII, o objetivo dos comerciantes portugueses já não são apenas os panos indianos, mas também o comércio com a China, mais concretamente o comércio de chá com a Europa.

Esse renovado interesse pelo Oriente era fruto da reunião de fatores conjunturais internos e externos, como a política bélica europeia ou os contextos de crise económica vividos na segunda metade do século XVIII em Portugal. Os comerciantes portugueses, sobretudo aqueles com maior dimensão, souberam aproveitar as oportunidades trazidas por tais circunstâncias, justificando-se assim o ressurgimento do interesse português pelo Oriente.

Quisemos sobretudo neste trabalho abordar o tema do financiamento dessas viagens. Se por um lado, Bohorquez conseguiu demonstrar uma forma de custear os empreendimento, sobretudo alicerçado numa escala global, em que participavam capitais com diferentes origens, focados num circuito entre quatro pontos (a Europa, a América, a Ásia e a África), onde a prata, os panos e os escravos eram a locomotiva do negócio, por outro, vemos que isso não é suficiente para justificar o interesse pelos negócios na China. O que percebemos, apesar das parcas fontes, é que os portugueses encontraram outra forma de financiamento.

Os livros dos "Trovoada Pequeno" deram-nos, então, conta que os navios partiam de Lisboa carregados de produtos europeus, carga a ser completada nas paragens dos portos atlânticos (Ilha da Madeira e Rio de Janeiro), seguindo depois viagem para o Índico. Era ali que pela venda dos ditos efeitos se obtinha a prata e 
as letras para comerciar na China. Esta é uma ideia reforçada pelos casos apresentados pela historiografia para as viagens realizadas pelas companhias de comércio colonial portuguesas, mas também as estrangeiras, nomeadamente a Companhia Dinamarquesa e a Sueca.

Aquilo que concluímos na nossa análise, assente nos livros da negociação de dois navios, é que o envolvimento de capitais lisboetas tem um elevado peso, bem como as estratégias para participar nesse negócio que evitava estar dependente de capitais maioritariamente estrangeiros ou coloniais.

Concluímos também que, tal como já tinha alertado Jorge Pedreira, as redes têm um papel preponderante. Percebemos que elas têm um relevo determinante particularmente no acesso ao mercado chinês, pois eram os comerciantes de Macau, correspondentes de Lisboa, que viabilizavam a viagem ao aceitarem descontar ali as letras que lhes chegavam pelas mãos dos sobrecargas, convertiam-nas na prata que era utilizada para comprar o chá, produto chave na torna viagem.

\section{Referências bibliográficas}

ALBUQUeRQUE, Tomás Pinto de (2019), “Negociar a partir do dentro: a Casa Comercial de Jacinto Fernandes Bandeira (1775-1806)", in Bruno Lopes, Roger Lee de Jesus (eds.), Finanças, economia e instituições no Portugal moderno: séculos XVI-XVIII, Coimbra, Imprensa da Universidade de Coimbra / Coimbra University Press, 309-339.

ALVES, Jorge M. Santos (1998), “Diplomacia e comércio em Macau na Ásia do Sudeste, em inícios do século XIX, in Maria Johanna Schouten (org.), A Ásia do Sudeste. História, cultura e desenvolvimento, Lisboa, Veja, 129-138.

BOHORQUEZ, Jesus (2020a), "Linking the Atlantic and Indian Oceans: Asian Textiles, Spanish Silver, Global Capital, and the Financing of the Portuguese-Brazilian Slave Trade (1760-1808)", Journal of Global History, 15(1), 19-38.

BOHORQUEZ, Jesus (2020b), "Rio de Janeiro and the Silver Mining Economy of Potosi: Trans-Imperial, Global, and Contractual Approaches to South Atlantic Markets (18th Century)", Almanack, 24.

CARREIRA, António (1988), A Companhia Geral do Grão-Pará e Maranhão, São Paulo, Companhia Editora Nacional.

CARREIRA, Ernestina (1995), "O comércio português no Gujarate na segunda metade do século XVIII: As famílias Loureiro e Ribeiro", Mare Liberum, 9, 83-94.

CHAUDHURI, Sushil (1998), "The Inflow of Silver to Bengal in the Global Perspective c.1650-1757", in Clara Eugenia Núñez (ed.), Histoire Monétaire: Une Perspective Globale, 1500-1808, Sevilla, Universidad de Sevilla, 85-96.

COSTA, Fernando Dores (1992), A crise financeira, dívida pública e capitalistas (1796-1807), Dissertação de Mestrado, Lisboa, Faculdade de Ciências Sociais e Humanas da Universidade Nova de Lisboa.

COSTA, Leonor Freire (1997), Naus e galeões na ribeira de Lisboa: a construção naval no século $X$ VI para a Rota do Cabo, Cascais, Patrimonia.

COSTA, Leonor Freire (2002), O transporte no Atlântico e a Companhia Geral do Comércio do Brasil, 1580-1663, Vol. I, Lisboa, Comissão Nacional para as Comemorações dos Descobrimentos Portugueses.

COSTA, Leonor Freire (2013), “Portuguese Resilience in Global War: Military Motivation and Institutional Adaptation in the Sixteenth- and Seventeenth-Century Cape Route", in Lucia Coppolaro, Francine 
McKenzie (eds.), A Global History of Trade and Conflict since 1500, London, Palgrave Macmillan, 38-61.

COSTA, Leonor Freire, ROCHA, Maria Manuela, SOUSA, Rita Martins de (2013), O Ouro do Brasil, Lisboa, Imprensa Nacional, Casa da Moeda.

CRANMER-BYANG, John L., WILLS, John E. (2011), "Trade and Diplomacy with Maritime Europe 1644c.1800", in John E. Wills (ed.), China and Maritime Europe 1500-1800, Cambridge, Cambridge University Press, 183-254.

CUNHA, João Manuel de Almeida Teles e (2006a), “A Carreira da Índia e Goa - apogeu e declínio crepusculares (1760-1835)", in Joel Serrão, A. H. de Oliveira Marques (dirs.), Nova História da Expansão Portuguesa, Vol. V, Tomo 1, Lisboa, Estampa, 361-449.

CUNHA, João Manuel de Almeida Teles e (2006b), "A rede económica do estado da Índia (1660-1750)", in Joel Serrão, A. H. de Oliveira Marques (dirs.), Nova História da Expansão Portuguesa, Vol. V, Tomo 1, Lisboa, Estampa, 162-339.

DIAS, Thiago Alves (2019), "Os negócios globais de uma companhia colonial: a Companhia Geral de Pernambuco e Paraíba e os negócios da China (1759-1783)", Afro-Ásia, 59, 131-167.

DOMINGUES, Francisco Contente (2015), "A Carreira da Índia. Percursos comparativos de uma empresa marítima", in Amândio Jorge Morais Barros (coord.), Os Descobrimentos e as Origens da Convergência Global, Porto, Câmara Municipal do Porto, 111-126.

DREIJER, Gijs (2017), Bargaining for Shelter. An Entrepreneurial Analysis of the Ostend Company, 1714-1740, MA Thesis, Leiden, Leiden University.

FIGUEIREDO, Fernando (2000), "Os vectores da economia”, in A. H. Oliveira Marques (dir.), História dos Portugueses no Extremo Oriente, Vol. III, Lisboa, Fundação Oriente, 95-298.

GODINHO, Vitorino Magalhães (1968), "Portugal, as frotas do açúcar e as frotas do ouro (1670-1770)”, in Ensaios II, Lisboa, Livraria Sá da Costa, 294-315.

GONZÁLES DE LARA, Yadira (2018), "Business Organization and Organizational Innovation in Late Medieval Italy", in Harwell Wells (ed.), Research Handbook on the History of Corporate and Company Law, Cheltenham, Northampton MA, Edmard Elgar Publishing, 65-87.

GUIMARÃES, Ângela (2000), Uma relação especial. Macau e as relações Luso-Chinesas (17801844), Lisboa, Centro de Investigação e Estudos de Sociologia.

GUINOTE, Paulo Jorge Alves, FRUTUOSO, Eduardo, LOPES, António (2002), As armadas da Índia: 1497-1835, Lisboa, Comissão Nacional para as Comemorações dos Descobrimentos Portugueses.

HARRIS, Ron (2020), Going the Distance: Eurasian Trade and the Rise of the Business Corporation, 1400-1700, Princeton, Princeton University Press.

HODACS, Hanna (2016), Silk and Tea in the North: Scandinavian Trade and the Market for Asian Goods in Eighteenth-Century Europe, London, Palgrave Macmillan.

KONINCKX, C. (2007), "Sweden and India in the Eighteenth Century: Sweden's Difficulty in Gaining Access to a Crowded Market", in Merchants, Companies and Trade Europe and Asia in the Early Modern Era, Cambridge, Cambridge University Press, 212-226.

LAPA, José Roberto Amaral (1968), A Bahia e a Carreira da Índia, São Paulo, Companhia Editora Nacional.

MACEDO, Jorge Borges de (1951), A situação económica no tempo de Pombal: alguns aspectos, Lisboa, Livraria Portugália.

MADUREIRA, Nuno Luís (1997), Mercado e privilégios. A indústria portuguesa entre 1750-1834, Lisboa, Estampa.

MIRANDA, Susana Munch (2002), "Os circuitos económicos”, in A. H. Oliveira Marques (dir.), História dos Portugueses no Extremo Oriente, Vol. II, Lisboa, Fundação Oriente, 259-288.

NEVES, José Acúrsio das (1814), Variedades, sobre objectos relativos ás artes, commercio, e manufacturas: consideradas segundo os principios da economia politica, Lisboa, Impressão Regia. 
PEDREIRA, Jorge Miguel Viana (1991), "Indústria e negócio: a estamparia na região de Lisboa, 17801880", Análise Social, 26, 537-559.

PEDREIRA, Jorge Miguel Viana (1995), Os homens de negócios da praça de Lisboa. De Pombal ao Vintismo (1755-1822). Diferenciação, reprodução e identificação de um grupo social, Tese de Doutoramento, Lisboa, Faculdade de Ciências Sociais e Humanas da Universidade Nova de Lisboa.

PINTO, Celsa (1994), Trade and Finance in the Portuguese India. A Study of the Portuguese Country Trade 1770-1840, Nova Deli, Concept Publishing Company.

PINTO, Celsa (1995), "Lisbon Investment in the Indian Textile Commerce: the Surat Feeder", Mare Liberum, 9, 217-233.

PINTO, Celsa (2006), "Rede económica do Estado da Índia: 1750-1830”, in Joel Serrão, A. H. de Oliveira Marques (dirs.), Nova História da Expansão Portuguesa, Vol. V, Tomo 1, Lisboa, Estampa, 339-380.

PIRES, Benjamin Videira (1993), A vida marítima de Macau no século XVIII, Macau, Instituto Cultural de Macau \& Museu Marítimo de Macau.

PRITCHARD, E. H. (1934), "The Struggle for Control of the China Trade During the Eighteenth Century", Pacific Historical Review, 3(3), 280-295.

ROOVER, Reymound (1963), "The Organization of Trade”, in M. M. Postan, E. E. Rich, Edward Miller (eds.), The Cambridge Economic History of Europe, Vol. III, Cambridge, Cambridge University Press, 42-118.

SOUSA, Rita Martins de (2011), "A prata no século do ouro - Portugal (1700-1797)", in Álvaro Garrido, Leonor Freire Costa, Luís Miguel Duarte (eds.), Estudos de Homenagem a Joaquim Romero de Magalhães. Economia, Instituições e Império, Coimbra, Almedina, 391-404.

SOUZA, George Bryan (2010), "Merchants and Commerce in Asia and the Portuguese Empire over the Long 18th Century", Review of Culture, 34, 7-19.

TEIXEIRA, Manuel (1969), Macau e a sua dioceses, O culto de Maria em Macau, Macau, Tipografia da Missão do Padroado.

VALE, António Martins (1997), Os Portugueses em Macau (1750-1800), Lisboa, Instituto Português do Oriente.

VALE, António Martins (2006), "Macau”, in Joel Serrão, A. H. de Oliveira Marques (dirs.), Nova História da Expansão Portuguesa, Vol. V, Tomo 2, Lisboa, Estampa, 333-433. 